\title{
PATtern Of EpISTAXIS In SOKOTO, Nigeria: A REVIEW OF 72 CASES
}

\author{
K. R. Iseh and Z. Muhammad
}

Department of Ear, Nose and Throat, Usmanu Danfodiyo University Teaching Hospital, Sokoto, Nigeria Reprint requests to: Dr. K. R. Iseh, Department of Ear, Nose and Throat, Usmanu Danfodiyo University Teaching Hospital, Sokoto, Nigeria. E-mail: frobih@yahoo.com

\begin{abstract}
Background: Epistaxis remains a common otorhinolaryngological emergency in most hospital emergency departments with varied manifestations. The pattern as seen in a tertiary health institution in sokoto, Nigeria is the subject of this paper.

Method: This is a 5year retrospective study (January 1995-December 1999) of all cases of epistaxis presenting at or referred to the Ear, Nose and Throat (ENT) Department of Usmanu Danfodiyo University Teaching Hospital (UDUTH) Sokoto, Nigeria whose data were analyzed.

Results: A total number of 72 cases were seen with epistaxis out of 3,706 new cases seen at the ENT clinic. The incidence of epistaxis amongst UDUTH ENT patients was 19/1000.There were 45 males(62.5\%) and 27 Females(37.5\%) with a male to female ratio of 1.7:1. Their ages ranged between 1and 70 years with the $0-10$ age range recording the highest number (26.4\%). The commonest cause of epistaxis was idiopathic(29.2\%),followed by trauma(27.8\%) and hypertension(18.0\%).Non surgical methods(97.2\%) such as observation alone (34.7\%)without active intervention to arrest bleeding, and nasal packing(34.7\%), being the commonest intervention measures used to actively arrest bleeding followed by cauterization of the bleeding points(11.1\%) were the frequent treatment measures. Surgical extirpation was carried out in 2 cases (2.8\%) to arrest the epistaxis

Conclusion: Although epistaxis is a common otorhinolaryngological emergency and varied in its manifestation, it affects mainly the young people (<30years $\{62.5 \%\})$ in this environment with idiopathic, trauma, and hypertension being the common causes which are amendable to treatment with excellent results.
\end{abstract}

Key words: Epistaxis, patterns, Sokoto, Nigeria

Résumé

Contexte: L'épistaxis demeure une urgence otorhinolaryngologique commune des les services d'urgence de la plupart des hôpitaux avec des manifestations variées. Le mode de présentation observé dans une structure de santé tertiaire à Sokoto au Nigeria a fait l'objet de ce travail.

Méthode: Il s'agit d'une étude rétrospective sur 5 ans (de janvier 1995 a décembre 1999) de tous les cas d'épistaxis consultant ou adresses au service d'Otorhinolaryngologie (ORL) du Centre Hospitalier Universitaire (CHU) d'Usmanu Dan Fodiyo de Sokoto dont les données ont été analysées.

Résultats: Au total 72 cas d'épistaxis sur 3706 nouveaux cas ont été enregistrés au service d'ORL. L'incidence de l'épistaxis parmi les patients du service d'ORL du CHU Usmanu Dan Fodiyo était de 19/1000. Il y avait 45 hommes (62,5\%) et 27 femmes (37,5\%) avec un sexe ratio de 1,7 homme pour 1 femme. L'âge variait de 1 à 70 ans avec un pic de fréquence pour la tranche d'âge de 0 à 10 ans (26,4\%). L'étiologie la plus fréquente d'épistaxis était idiopathique $(29,2 \%)$, suivie par les traumatismes $(27,8 \%)$ and l'hypertension $(18,0 \%)$. Les méthodes non chirurgicales $(97,2 \%)$ telle que la mise en observation seule $(34,7 \%)$ sans méthode d'arrêt du saignement, et le tamponnement nasal $(34,7 \%)$ ont été les moyens couramment mis en œuvre pour arrêter le saignement. Elles ont été suivies par la cautérisation des zones hémorragiques $(11,1 \%)$. Un geste chirurgical a été effectue dans 2 cas $(2,8 \%)$ pour arrêter l'épistaxis. 
Conclusion: Quoique l'épistaxis soit une urgence ORL commune et de manifestations variées, elle affecte surtout le sujet jeune $(<30$ ans $\{62,5 \%\})$ dans ce contexte. Les causes idiopathiques, les traumatismes et l'hypertension sont les causes les plus fréquentes accessibles au traitement avec d'excellents.

Mots clés: Epistaxis, présentation, Sokoto, Nigeria

\section{Introduction}

Epistaxis (nose bleeding) is not new to man. Its occurrence could be frightening to the patient and observers nearby. It is estimated from a Scandinavian survey in 1974 of 410 people that up to $60 \%$ of the population will experience one episode of epistaxis in their lifetime and 6\% will seek medical attention. ${ }^{1,2} \mathrm{~A}$ US health examination survey from 1972 of 6672 adults revealed a $7 \%$ to $14 \%$ incidence of epistaxis. ${ }^{1}$ The general incidence from most reports from Europe and America is about $10 \%-15 \%$ of the population. ${ }^{3-5}$ Although epistaxis may occur at any age or at any time and in any season, it is a common complaint in the pediatric age group and the winter months but has been shown to have bimodal age range presentation in reports from north America and Europe. ${ }^{3-6}$ It is a frequent otolaryngologic emergency, which in serious cases will need a full complement of resuscitative measures to stabilize the patient and prevent or address hypovolaemic shock. Knowledge of history of epistaxis in a patient will assist the physician or surgeon in taking precautions while planning any treatment modality be it medical or surgical. Failure to take these precautions may lead to unpleasant consequences.

Epistaxis could be spontaneous or induced. ${ }^{3-7}$ It could be as a result of pathological disorder such as Hemophilia, or idiopathic when there is no known cause. It could be caused by a local disorder within the nose and paranasal sinuses or a result of a systemic disorder. ${ }^{3-7}$ Epistaxis could be unilateral or bilateral, mild, moderate, severe or torrential. Generally speaking, epistaxis could be as a result of congenital deficiencies in the clotting factor or vessel structure or acquired from trauma, infections etc.

The pattern of epistaxis as seen in Usmanu Danfodiyo University Teaching (UDUTH) Sokoto Nigeria is presented in this paper. The findings are compared with reports from other centers.Usmanu Danfodiyo University Teaching Hospital Sokoto is a tertiary health care facility located in the northwestern part of Nigeria. It is a referral center to many primary, secondary and private health facilities located in the region. Therefore only cases that deserved the attention of the teaching hospital were seen. Several other episodes of epistaxis that either resolved spontaneously or were managed at peripheral hospitals do not get to the teaching hospital.

\section{Materials and Methods}

This is a 5-year retrospective study of all cases of epistaxis presenting at or referred to the Ear, Nose and Throat (ENT) Department of Usmanu Danfodiyo University Teaching Hospital (UDUTH) Sokoto from January, 1995 to December, 1999. The case folders of 72 cases were analyzed for demographic data, clinical presentation and their management.

Investigations included Full Blood Count, bleeding time, clotting time, prothrombin time, X-rays of paranasal sinuses. Other investigations such as serum electrolytes, urea and creatinine, electrocardiography, chest radiographs, bone marrow aspiration liver function tests were carried out as the clinical situation demanded. Some patients received only medical and conservative management while others required surgical intervention.

\section{Results}

The total number of ENT patients seen in the department during the period was 3706 out of which 72 were cases of epistaxis. The incidence of epistaxis among UDUTH ENT patients was 19/1000. There were 45 males (62.5\%) and 27 females (37.5) with male to female ratio of $1.7: 1$. Their ages ranged between $1 \mathrm{yr}$ and 70years with patients less than $10 y r s$ accounting for $26.4 \%, 11-20 y r s$ age range $19.4 \%$ and $21-30$ years $16 \%-7 \%$ as shown in Table 1.

The commonest cause of epistaxis was Idiopathic (29.2\%) followed by trauma (27.8\%) and hypertension (18.0\%) as shown in Table 2.

Non surgical measures were the main intervention methods in $97.2 \%$ of the cases(Table 3).Out of this no active intervention to arrest bleeding except observation, systemic nasal decongestants(antihistamines), and antibiotics was carried out in 25cases(34.7\%), while active intervention was carried out in 47 cases(65.3\%). Nasal packing in 25 cases(34.7\%) was the commonest non surgical active intervention measure used to arrest bleeding followed by cauterization in 8 cases(11.1\%). Others were parenteral vitamin $\mathrm{K}$ in 8 cases(11.1\%), eucalyptus oil steam inhalation in 2 cases(2.8\%) and Blood transfusion in 2 cases(2.8\%). Surgical resection of tumor was the definitive treatment in 2 cases (2.8\%). 
Table 1. Age distribution of 72 patients with epistaxis in Sokoto, Nigeria

\begin{tabular}{lll}
\hline Age (years) & No. & \% \\
\hline $0-10$ & 19 & 26.4 \\
$11-20$ & 14 & 19.4 \\
$21-30$ & 12 & 16.7 \\
$31-40$ & 13 & 18.0 \\
$41-50$ & 8 & 11.1 \\
$51-60$ & 4 & 5.6 \\
$61-70$ & 2 & 2.8 \\
\hline Total & 72 & 100 \\
\hline
\end{tabular}

Table 3. Treatment of epistaxis in Sokoto, Nigeria
Table 2. Causes of epistaxis in 72 patients in Sokoto, Nigeria

\begin{tabular}{ll}
\hline Causes & No. (\%) \\
\hline Idiopathic & $21(29.2)$ \\
Trauma & $20(27.7)$ \\
Hypertension & $13(18.0)$ \\
Chronic rhinosinusitis & $8(11.1)$ \\
Bleeding diathesis & $4(5.6)$ \\
Viral hepathatitis & $1(1.4)$ \\
Nasal polyps & $1(1.4)$ \\
Nasal papilloma & $1(1.4)$ \\
Septal granuloma & $1(1.4)$ \\
Sickle cell disease & $1(1.4)$ \\
Vitamin deficiency & $1(1.4)$ \\
\hline Total & $72(100)$ \\
\hline
\end{tabular}

\begin{tabular}{|c|c|}
\hline Treatment & No. (\%) \\
\hline \multicolumn{2}{|l|}{ Non-surgical measures } \\
\hline $\begin{array}{l}\text { No active intervention at bleeding site (General measures: systemic antibiotics, nasal } \\
\text { decongestant specific medical treatment e.g. antihypertensive therapy) }\end{array}$ & $25(34.7)$ \\
\hline Active intervention at bleeding site & $45(62.5)$ \\
\hline Nasal packing & $25(34.7)$ \\
\hline \multicolumn{2}{|l|}{ Anterior (24) } \\
\hline \multicolumn{2}{|l|}{ Posterior (1) } \\
\hline Cauterization & $8(11.1)$ \\
\hline \multicolumn{2}{|l|}{ Chemical with silver nitrate(7) } \\
\hline \multicolumn{2}{|l|}{ Electrical (1) } \\
\hline \multicolumn{2}{|l|}{ Vitamin $\mathrm{K}$} \\
\hline Eucalyptus oil steam inhalation & $2(2.8)$ \\
\hline Blood transfusion (given in conjunction with other treatment modalities & $2(2.8)$ \\
\hline Surgical resection of tumour & $2(2.8)$ \\
\hline Total & $72(100)$ \\
\hline
\end{tabular}

\section{Discussion}

Although epistaxis is a common otorhinolaryngological emergency, many episodes are self limiting and spontaneous arrest of bleeding may occur and so may not need any medical or surgical intervention to arrest the bleeding. In about 25 cases $(34.7 \%)$ in this study, there was no need for any active intervention to arrest nose bleeding. It is advisable to observe such patients while at the same time carry out a thorough general and otorhinolaryngological examination to investigate the cause of epistaxis.In some cases a small ruptured vessel can be found that are usually minor and are easily controlled. Any case of epistaxis in which the bleeding has been continuous for several hours or is coming from the nasopharyngeal area demands active attention and therapy irrespective of the cause.
The commonest cause of epistaxis from this report in Sokoto Nigeria was idiopathic (29.2\%), followed by trauma (27.8\%), and hypertension (18.0\%). Findings in most western literature, cites idiopathic causes as the commonest, followed by trauma ${ }^{1-6}$.ljaduola in Lagos Nigeria reported idiopathic as the next commonest cause of epistaxis after trauma particularly among young people. ${ }^{8,9}$ Young people are the most active in the population and so are more vulnerable to trauma from nose picking especially among children, fights, road traffic accident with faciomaxillary injuries causing epistaxis. Most first aid measures carried out at the Accident and Emergency unit such as pinching of the nose, anterior nasal packs with gauze or cotton wool sometimes soaked with adrenaline usually controls most nose bleedings from trauma. Few cases may still require the attention of the otorhinolaryngologist as was the case of 20 patients $(27.7 \%)$ in this series. 
Hypertension being the third commonest cause in this report shows epistaxis as evidence of poor blood pressure control. This collaborates with an earlier report also from Lagos in Nigeria of some patients who had epistaxis when their hypertension was not controlled due to ceasation of antihypertensive drug therapy. ${ }^{8,9}$ The need for regular blood pressure check and compliance to antihypertensive medications must be emphasized. Varsney and Saxena in Dehradun India recorded hypertension as the second commonest cause of epistaxis after idiopathic causes while Chaiyasate et al reported hypertension to be the commonest cause of epistaxis followed by idiopathic causes in the Chiang Mai University Hospital Thailand. ${ }^{2,8}$

Chronic rhinosinusitis was the fourth cause of epistaxis in this report. Congestion of the nasal mucosa with or without formation of crusts predisposes to epistaxis. Most of these patients do well on medical treatment .Bleeding diathesis from blood dyscrasias was noted in 4 patients just as viral hepatitis, sickle cell anemia and vitamin deficiency from malnutrition were recorded as some causes of epistaxis underscores the need for a thorough hematological and biochemical evaluation in such cases. These set of patients require a combination of several medical treatments.

The possibility of epistaxis as a result of underlying neoplasm must always be borne in mind particularly from sinonasal and nasopharyngeal region as well as hematological malignancies such as leukemias. ${ }^{1-10}$ Sinonasal or nasopharyngeal tumor whether benign or malignant (except for nasopharyngeal carcinoma) may require surgical resection. Surgical resection was carried out in 2 cases that had sinonasal tumor. When the lesion is malignant as in nasopharyngeal carcinoma radiotherapy is the treatment of choice. Nasopharyngeal cancers are known causes of epistaxis. They usually present with cervical lymphadenopathy, rhinological symptoms (epistaxis and nasal obstruction) and otological symptoms (otorrhoea and deafness). Martinson's work in Ibadan in Nigeria was the first detailed report on epistaxis and nasopharyngeal cancers in Nigeria ${ }^{9}$.Other causes such as nasal foreign bodies which is common in children and patients on anticoagulant therapy though not recorded in this series should be searched for.

There were more males than females with male to female ratio of $1.7: 1$. which is almost similar to the report of Ijaduola ${ }^{10}$ who had a male to female ratio of 1.5:1 in Lagos Nigeria. Globally there is a male preponderance in epistaxis except in the geriatric age group in some reports where no significant sex difference exists. ${ }^{1-6}$ Majority of patients seen in this series were young people less than 30years of age (62.5\%) with patients less than $10 y$ rs accounting for
26.4\%..Varshney and Saxena in Dehradun in India reported most of their patients to be older than 40 years (63.64\%) with a mean age of 47.8 years which correlates with other reports which showed that epistaxis is a geriatric problem ${ }^{2}$.

Selection of the adequate approach to the patient with severe epistaxis must consider 3 parameters: efficiency, complications, and cost benefit. ${ }^{2,11}$ Nasal packing has the advantage of easy placement and removal using our hands, its efficiency is closer to $45 \%{ }^{2}$.Nasal packing ( 24 anterior $(42.6 \%), 1$ posterior) was the commonest mode of treatment to arrest bleeding out of the $47(65.3 \%)$ cases that required active intervention. Even though various methods abound in treating epistaxis, anterior nasal packing is generally the most frequent intervention in the immediate treatment of epistaxis, pending detailed information of the cause from investigations and institution of other appropriate treatment measures.

No surgical ligation of any vessel was carried out on any patient in this study. Arterial ligation is necessary in intractable cases of epistaxis when conservative measures have failed. ${ }^{1-17}$ Failure rate of $10 \%-14 \%$ has been reported with arterial ligation mainly because of inappropriate selection of the vessel. ${ }^{2,6,8,9,12-17}$ The rich vascular network of the nasal mucosa allows for a new flow distribution after ligation of the vessel and this may maintain the hemorrhage leading to multiple unsuccessful vascular ligations. ${ }^{2}$ Currently endoscopic approach backed by image guiding devices, and intervention radiology has made arterial ligation safer, and faster in the management of epistaxis. ${ }^{1,2,13,15-17}$

The need for resuscitation in cases of severe or torrential epistaxis should be emphasized to prevent hypovolaemic shock and fatal outcome. Prompt evaluation of quantity of blood loss and timely intervention is crucial in the management of epistaxis. There may be the need for blood transfusion. The benefits to the patient must be weighed against the risks and also the religious beliefs of the patient. Caution must be exercised in sickle cell patients to avoid volume overload. There was no mortality recorded in this report. A mortality rate of $1.9 \%$ was reported in a study in Lagos Nigeria due to severe epistaxis from terminal phase of diphtheria. ${ }^{10}$

\section{Conclusion}

Epistaxis in this environment is mostly a disease of young people. Idiopathic cause, trauma, hypertension are the commonest causes in our environment. Hypertension control in our environment should therefore be taken seriously. Anterior nasal packing is still useful to arrest bleeding pending appropriate investigation of the cause and treatment but one must be prepared for other measures should conservative measures fail. 


\section{References}

1. Santos PM, Lepore ML. Epistaxis. In: Bailey BJ, Calhoun KH (Eds). Head and Neck Surgery otolaryngology.

Lippincott-Raven, Philadelphia.1998; 513-529.

2. Varshney S, Saxena RK. Epistaxis: a retrospective clinical study. Indian Journal of Otolaryngology, Head Neck Surgery. 2005; 57:125-129.

3. Maran AGD, Lund VJ. Clinical rhinology. Thieme Medical Publishers, New York. 1990; 101-103.

4. Watkinson JC. Epistaxis. In: Kerr AG, Mackay IS, Bull TR (Eds). Scott-Brown's otolaryngologyrhinology. Butterworth-Heinemann, London.1997:1-19.

5. Roland NJ, McRae RDR, McCombe AW. Key topics in otolaryngology and head and neck surgery. Bios Scientific Publishers, Oxford. 2001; 72.

6. Culbertson MC, Manning SC. Epistatxis. In: Bluestone CD, Stool SE (Eds). Paediatric otolaryngology. W.B. Saunders, Philadelphia. 1990; 672-679.

7. Gray RF, Hawthorne M. Synopsis of otolaryngology. Butterworth- Heinemann, London. 1992:261-265.

8. Chaiyasate $S$, Roongrotwattanasiri K, Fooanan S, Sumitsawan Y. Epistaxis in Chiang Mai university. J Med Assoc Thai. 2005; 88:1282-1286.

9. Martinson FD. Cancer of the nasopharynx in
Nigeria. J Laryngol Otol. 1968; 82:1119-1128.

10. Ijaduola GTA. Okeowo PA. Pattern of epistaxis in the tropics. Cent Afr J Med. 1983; 29:77-80.

11. Ijaduola GTA. Management of epistaxis in General practice. Nigerian Medical Practitioner. 1986; 26:21-25.

12. Schaitkin B, Strauss M, Houck JR, Hershey PA. Epistaxis: medical versus surgical therapy: a comparison of efficacy, complications, and economic considerations. Laryngoscope. 1987; 97:1392-1396.

13. Srinivasan V, Sherman IW, O'Sullivan G. Surgical management of intractable epistaxis: audit of results. J Laryngol Otol. 2000; 114:697-700.

14. Rosnagle RS, Yanagisawa EY, Smith HW. Specific vessel ligation for epistaxis: surgery of 60 cases. Laryngoscope. 1973; 83:517-525.

15. Safaya A, Venkatchalam VP, Chaudhary N. Nasal endoscopy-evaluation in epistaxis. Indian Journal of Otolaryngology, Head Neck Surgery. 2000; 52:133-136.

16. Pritikin JB, Caldarelli DD, Panie WR. Endoscopic ligation of the internal maxillary artery for treatment of intractable posterior epistaxis. Ann Otol Rhinol Laryngol. 1998; 107:85-91.

17. El-Guindy A. Endoscopic transseptal sphenopalatine artery ligation for intractable posterior epistaxis. Ann Otol Rhinol Laryngol. 1998; 107:1033-7. 